\title{
Effect of $\mathbf{I}_{2}$ Plasma on the Properties of Polyethylene
}

\author{
Motoi Fujishima, Daigo Kawabata, Chihiro Funakoshi, Yasuhiko Yoshida, \\ Tadataka Yamashita, Kunihiro Kashiwagi, and Kanto HigashiKata* \\ Department of Applied Chemistry, Faculty of Engineering, Toyo University, \\ Kawagoe, Saitama 350, Japan \\ *C. Itoh Fine Chemical Co. Ltd., 3-29 Kioicho, Chiyoda-ku, Tokyo 102, Japan
}

(Received October 4, 1994)

\begin{abstract}
Polyethylene surfaces were treated with $I_{2}$ plasma. From ESCA analysis, it became apparent that iodine atoms were bound chemically to the surface of polyethylene substrate by the treatment of $I_{2}$ plasma. Also, iodine bonded chemically to polyethylene increased by the exposure of $I_{2}$ vapor after $I_{2}$-plasma treatment of the substrate. The reaction of $I_{2}$-plasma treated polyethylene with aminoalcohol made the polyethylene substrate hydrophilic.
\end{abstract}

KEY WORDS Plasma / Iodine / Surface / Treatment / Polymer /

In glow-discharge low-temperature plasma, atoms and/or molecules are activated to give ions, radicals or excited species. Plasma are expected to be applied in various fields, such as forming thin films with high functionality, etching a substrate surface, and treating the surface of organic material substrates. Though plasma chemistry has been widely investigated, further studies on plasma chemistry are required in order to create the various functional thin films or surfaces.

Recently, plasma treatment of polymer has been done to introduce various functionalities onto the surface of organic materials. Functionalities, such as wettability, water repellency and adhesion, are attributed to chemical structures and functional groups on polymer surface. Plasma treatment of a polymer is useful method for reforming a polymer surface, which changes the surface properties of an organic material, such as hydrophobicity or hydrophilicity. The treatment of the organic materials by $\mathrm{O}_{2}, \mathrm{~N}_{2}$, or Ar plasma produces the functional groups, such as hydroxyl, carbonyl, amino or nitrile groups, and adds various functionalities, such as hydrophilicity, wettability or adhesion property. ${ }^{1,2}$ Plasma treatment of a polymer by fluorine derivatives such as tetrafluoromethane or fluorine is used for etching a material surface, and gives water repellency to polymer surface. ${ }^{3}$ Also, plasma treatment of organic materials by chloroform is reported. ${ }^{4}$ However, plasma treatment by iodine $\left(\mathrm{I}_{2}\right)$ gas has not been reported, although plasma polymerization using iodomethane was carried out to form thin films containing iodine linked chemically. ${ }^{5}$ This article reports that $\mathrm{I}_{2}$-plasma treatment of polymer forms organic materials linking chemically iodine atoms. The functionality of $\mathrm{I}_{2}$-plasma-treated polyethylene was investigated.

\section{EXPERIMENTAL}

As shown in Figure 1, the plasma apparatus is made of a pyrex glass, $5 \mathrm{~cm}$ in diameter and $40 \mathrm{~cm}$ in length, fitted with an iodine $\left(\mathrm{I}_{2}\right)$ gas inlet, argon (Ar) gas inlet, pressure gauge and vacuum system. The plasma was generated by application of a high voltage amplified by a neon transformer to the tungsten (W) electrodes. The plasma power was controlled using a variable resistor. The plasma apparatus was evacuated to about $200-400 \mathrm{mTorr}$, and then 


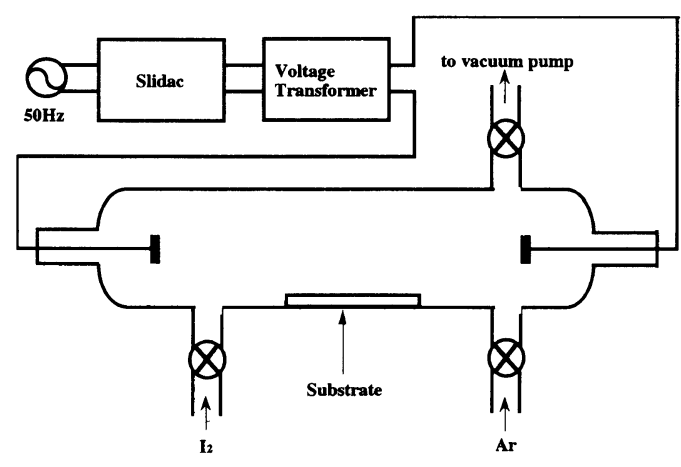

Figure 1. Schematic diagram of the apparatus for $\mathrm{I}_{2}$-plasma treatment.

the vapor of $\mathrm{I}_{2}$ sublimed at $0^{\circ} \mathrm{C}$ was introduced. Before the plasma treatment by $I_{2}$ vapor, the atmosphere was replaced with Ar gas. As a sample for ESCA analysis, polyethylene thin film (PE, $30 \mathrm{~mm} \times 25 \mathrm{~mm} \times 0.8 \mathrm{~mm})$ was used. The polyethylene substrate $(50 \mathrm{~mm} \times 25 \mathrm{~mm} \times$ $2 \mathrm{~mm}$ ) was used to measure the contact angle.

The reaction of the treated polyethylene with amine was carried out as follows. The $\mathrm{I}_{2}$ plasma-treated polyethylene substrate was placed in a beaker containing a solution of various amines $(200 \mathrm{ml})$ for a specified period. The substrate was washed by ethanol, and dried under reduced pressure.

ESCA spectra were recorded with a Shimadzu electron spectrometer, ESCA 750. Wettability of the treated polyethylene substrate was estimated by the contact angle with water. Contact angles with water were measured at room temperature using a contact-angle meter (ERMA Inc., Model G-I).

\section{RESULTS AND DISCUSSION}

\section{$I_{2}$-Plasma Treatment of Polyethylene}

Vapor of iodine $\left(\mathrm{I}_{2}\right)$ was introduced into the reactor without generating plasma, and the polyethylene substrate was exposed to $\mathrm{I}_{2}$ vapor. The polyethylene substrate was analyzed by ESCA. The iodine doublet at 630 and $619 \mathrm{eV}$ was not detected, thus showing that iodine did not link chemically and was not adsorbed

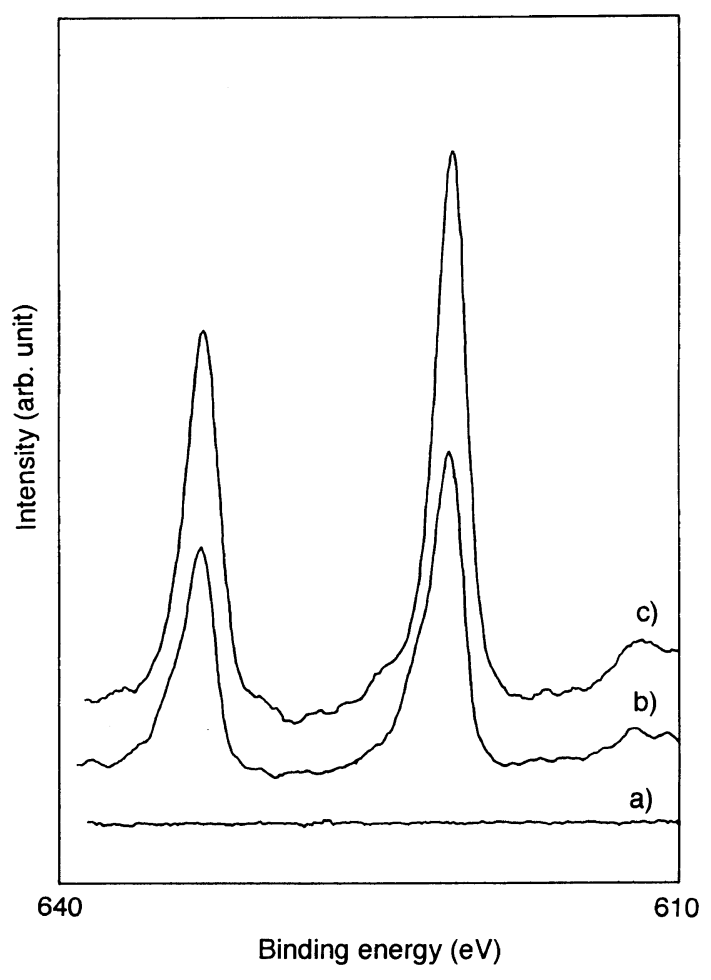

Figure 2. ESCA spectra of $I_{2}$-plasma, $I_{2}$-plasma $/ I_{2}-$ vapor-treated polyethylene and untreated polyethylene. a) polyethylene substrate without treatment; b) polyethylene substrate treated by $\mathrm{I}_{2}$-plasma for 1 hour; c) polyethylene substrate treated by $\mathrm{I}_{2}$-plasma for 1 hour and exposed to $\mathrm{I}_{2}$ vapor for 1 hour.

physically to the surface of the polyethylene substrate only by exposure of $\mathrm{I}_{2}$ vapor without plasma generation.

Polyethylene substrate was treated by $\mathrm{I}_{2}$ plasma at $200 \mathrm{mT}$ Torr. The $\mathrm{I}_{2}$-plasma-treated polyethylene was analyzed by ESCA. As shown in Figure 2b, $\mathrm{I}_{2}$-plasma-treated polyethylene showed peaks at $630.60 \mathrm{eV}$ and $619.10 \mathrm{eV}$, which were assigned to iodine atoms of $3 d_{3 / 2}$ and $3 d_{5 / 2}$ respectively. These peaks are indicative of iodine bonded chemically to carbon by $I_{2}$ plasma, since iodine was not detected on polyethylene exposed to $I_{2}$ vapor.

The iodine in polyethylene surface depended on the time of $\mathrm{I}_{2}$-plasma treatment. As shown in Figure 3, iodine became approximately constant at $25 \%$ at an $\mathrm{I} / \mathrm{C}$ molar ratio over 


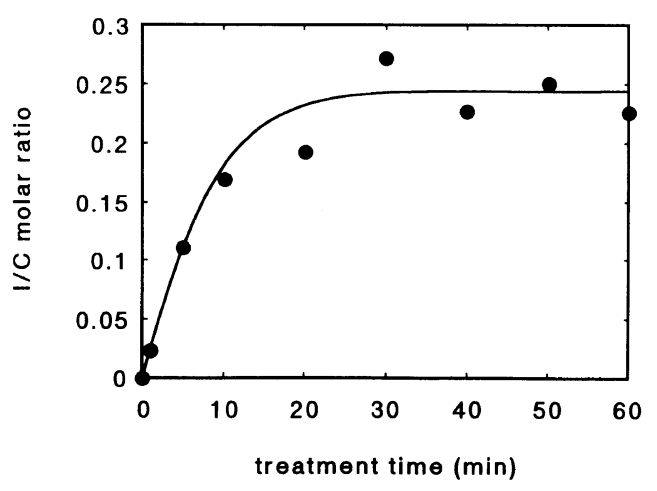

Figure 3. Effects of $I_{2}$-plasma treatment time on iodine bonded to polyethylene. (Plasma voltage, $3.6 \mathrm{kV}$ )

$20 \mathrm{~min}$.

The ac voltage applied to the $\mathrm{W}$ electrodes was set at $3.0 \mathrm{kV}, 3.6 \mathrm{kV}$, and $4.8 \mathrm{kV}$, because iodine bonded to the polyethylene was very low below $3.0 \mathrm{kV}$ and $\mathrm{I}_{2}$ plasma was unstable over $4.8 \mathrm{kV}$. At each plasma voltage, $I_{2}$-plasma treatment was carried out for $1 \mathrm{~h}$. Iodine bonded to polyethylene surface is shown in Table I. Iodine in polyethylene increased with plasma voltage.

The depth profile of iodine bonded to polyethylene was measured by varying the incident angle of X-ray to the surface of the polyethylene film. From Table II, it was confirmed that iodine was present at a depth of $c a .100 \AA$ from the topmost layer of the polyethylene surface. It has been reported that the escape depth of photoelectron is the outermost few tens of Angstroms of the sample (in the range $\sim 100 \AA$ ). ${ }^{6}$

\section{Treatment of Polyethylene by $I_{2}$ Plasma and $I_{2}$ Vapor}

Radical species are present at the surface of organic material treated by plasma and the life span is very long in comparison with that of the organic radical species. Halogen molecules are known to react easily with radical species.

The surface of the polyethylene substrate was treated for $1 \mathrm{~h}$ with $\mathrm{I}_{2}$ plasma generated at plasma voltages of $3.6 \mathrm{kV}$, and thereafter,
Table I. Surface composition of $\mathrm{I}_{2}$-plasma-treated and $I_{2}$-plasma $/ I_{2}$-vapor-treated polyethylene

\begin{tabular}{cccc}
\hline \multirow{2}{*}{$\begin{array}{c}\text { Plasma voltage } \\
(\mathrm{kV})\end{array}$} & $\mathrm{I}_{2}$-plasma $(1 \mathrm{~h})$ & & $\begin{array}{c}\mathrm{I}_{2} \text {-plasma }(1 \mathrm{~h}) / \\
\mathrm{I}_{2} \text {-vapor }(1 \mathrm{~h})\end{array}$ \\
\cline { 2 - 2 } & $\mathrm{I} / \mathrm{C}$ & $\mathrm{I} / \mathrm{C}$ \\
\hline 3.0 & 0.04 & 0.16 \\
3.6 & 0.22 & 0.43 \\
4.8 & 0.29 & - \\
\hline
\end{tabular}

Table II. Depth profile of $\mathrm{I}_{2}$-plasma-treated polyethylenes surface ${ }^{a}$

\begin{tabular}{ccccc}
\hline & $0^{\circ}(d)$ & $30^{\circ}(0.87 d)$ & $45^{\circ}(0.71 d)$ & $60^{\circ}(0.5 d)$ \\
\hline $\mathrm{I} / \mathrm{C}$ & 0.04 & 0.08 & 0.05 & 0.02
\end{tabular}

a $(d$, escape depth of photoelectron in the range $\sim 100 \AA)$.

iodine vapor was introduced into the reactor for $1 \mathrm{~h}$ without plasma generation. The surface of polyethylene substrate after this treatment was analyzed by ESCA. As shown in Figure 2 and Table II, exposure to $\mathrm{I}_{2}$ vapor after $\mathrm{I}_{2}$-plasma treatment caused the introduction of iodine more than that of iodine by $\mathrm{I}_{2}$-plasma treatment only. This suggests that $\mathrm{I}_{2}$-plasma treatment of polyethylene forms carbon-iodine bonds and radical species on polymer surface, and thereafter that radical species surviving on the polymer surface react with $I_{2}$ vapor introduced into the reactor without activation by plasma, to form the additional carboniodine bonds.

\section{Reactions of Polyethylene Containing Iodine with Amine Derivatives}

The hydrophobic/hydrophilic properties of $\mathrm{I}_{2}$-plasma-treated polyethylene or $\mathrm{I}_{2}$-plasma/ $\mathrm{I}_{2}$-vapor-treated polyethylene were determined by measurement of the contact angle with water. The contact angle with water ranged from 56 to $104^{\circ}$, because the contact angle depended on the amount of oxygen and iodine bonded to the polymer surface. To import hydrophilicity to the polymer surface, the 
reaction of polyethylene containing iodine with amine was carried out. Polyethylene containing iodine was prepared by $\mathrm{I}_{2}$-plasma treatment for $1 \mathrm{~h}$ at $3.6 \mathrm{kV}$ and thereafter treatment with $I_{2}$ vapor alone for another $1 \mathrm{~h}$ without plasma. Alkyl iodide easily reacts with amine to give the ammonium iodide salt, as follows.

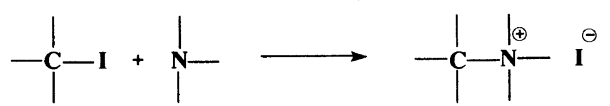

After reactions with various amines, iodine in polyethylene containing iodine decreased, and the introduction of nitrogen atoms to polyethylene substrate was apparent from the results of ESCA measurement (Table III). The nitrogen $\left(\mathrm{N}_{1 \mathrm{~s}}\right)$ peak appeared at $403 \mathrm{eV}$, which was assigned to the nitrogen atoms of ammonium salts. It is considered that the decrease of iodine contents resulted from the exchange reaction of iodide ion $\left(\mathrm{I}^{-}\right)$with hydroxide ion $\left(\mathrm{OH}^{-}\right)$and the elimination reaction of hydrogen iodide (HI) from polyethylene containing iodine by interaction of the amine. The contact angle with water decreased slightly, after reactions of $I_{2}$-plasma- $/ I_{2}$-vapor-treated polyethylene with amines (Table III, No. 1-3). Similarly, after reactions with aminoalcohol derivatives (No. $4-6$ ), iodine in polyethylene containing iodine decreased and nitrogen atoms were bound to polyethylene substrate. The contact angle with water decreased at all surfaces of the polyethylene substrate treated by $\mathrm{I}_{2}$-plasma-/ $\mathrm{I}_{2}$-vapor/aminoalcohol, causing the surface to become hydrophilic.

Treatment of polyethylene substrate by $\mathrm{I}_{2}$ plasma, $I_{2}$-plasma $/ I_{2}$-vapor, or $I_{2}$-plasma $/ I_{2}$ vapor/aminoalcohol makes it possible to change the hydrophobicity/hydrophilicity of polyethylene.
Table III. Elemental composition of substrate surface treated by the reaction of $\mathrm{I}_{2}$-plasma- $/ \mathrm{I}_{2}$-vapor-treated polyethylene with various amines ${ }^{\mathrm{a}}$

\begin{tabular}{llccc}
\hline \multirow{2}{*}{ Amines } & \multicolumn{2}{c}{ Element ratios } & Contact \\
\cline { 2 - 4 } & & $\mathrm{N} / \mathrm{C}$ & $\mathrm{I} / \mathrm{C}$ & \\
\hline 1 & $n$-Propyles \\
2 Isopropylamine & 0.20 & 0.03 & $76^{\circ}$ \\
3 Triethylamine & 0.31 & 0.06 & $58^{\circ}$ \\
4 & 2-Methylaminoethanol & 0.15 & 0.04 & $60^{\circ}$ \\
5 & 2-Dimethylaminoethanol & 0.43 & 0.03 & $24^{\circ}$ \\
6 & 2-Ethylaminoethanol & 0.33 & 0.04 & $27^{\circ}$ \\
& & & & $21^{\circ}$ \\
\hline
\end{tabular}

a $\mathrm{I}_{2}$-plasma $/ \mathrm{I}_{2}$-vapor treated polyethylene: $\mathrm{I} / \mathrm{C} ; 0.43$, contact angle; $73^{\circ}$.

\section{CONCLUSIONS}

In this study, iodine was bonded chemically to polyethylene surface by treatment of $\mathrm{I}_{2}$ plasma. By exposure of $\mathrm{I}_{2}$ vapor after $\mathrm{I}_{2}$ plasma treatment, more iodine than that by $\mathrm{I}_{2-}$ plasma treatment only became bound to the surface of polyethylene.

The $I_{2}$-plasma-treated polyethylene surface reacted with aminoalcohols, causing the surface to become hydrophilic.

\section{REFERENCES}

1. H. K. Yasuda, "Plasma Polymerization and Plasma Treatment of Polymers," J. Appl. Polym. Sci., Appl. Polym. Symp., 42 (1988).

2. Y. Nakagawa, Y. Yoshida, and T. Yamashita, Kobunshi Ronbunsyu, 46, 209 (1989); Y. Yoshida and Y. Nakagawa, "Proceedings of Japanese Symposium on Plasma Chemistry," Vol. 2, Organizing Committee Japanese Symosium on Plasma Chemistry, Ed., Shinzansha Scitech Co. Ltd., Tokyo, 1989, p 225.

3. M. Strobel, S. Corn, C. S. Lyons, and G. Korba, J. Polym. Sci., A, Polym. Chem. Ed., 25, 1295 (1987).

4. N. Inagaki, S. Tasaka, Y. Suzuki, J. Appl. Polym. Sci., 13, 51 (1994).

5. J. H. Dully, F. J. Wodarczyk, and J. J. Ratto, J. Polym. Sci., A, Polym. Chem. Ed., 25, 1187 (1987).

6. D. T. Clark, Adv. Polym. Sci., 24, 125 (1977). 